\title{
Effects of preventive home visits to elderly people
}

\author{
Erik van Rossum, Carla M A Frederiks, Hans Philipsen, Ko Portengen, Jannie Wiskerke, \\ Paul Knipschild
}

\begin{abstract}
Objectives-To assess the effect of preventive home visits by public health nurses on the state of health of and use of services by elderly people living at home.

Design-Randomised controlled trial.

Setting-General population of elderly people in one of the southern regions of the Netherlands.

Subjects-580 subjects aged between 75 and 84 years randomly allocated to intervention (292) or control (288) group.
\end{abstract}

Interventions-Four visits a year over three years in intervention group. Control group received no home visits.

Main outcome measures-Self rated health, functional state, well being, loneliness, aspects of the mental state (depressive complaints, memory disturbances), and mortality. Use of services and costs.

Results-Visits had no effect on the health of the subjects. In the group visited no higher scores were seen on health related measures, fewer died (42 $(14 \%) v 50(17 \%))$, and community care increased slightly. In the control group more were referred to outpatient clinics $(166(66 \%) v 132(55 \%))$, and they had a $\mathbf{4 0} \%$ increased risk of admission (incidence rate ratio $1 \cdot 4 ; 90 \%$ confidence interval $1 \cdot 2$ to $1 \cdot 6)$. No differences were found in long term institutional care, and overall expenditure per person in the intervention group exceeded that in the control group by $4 \%$. Additional analyses showed that visits were effective for subjects who initially rated their health as poor.

Conclusions-Preventive home visits are not beneficial for the general population of elderly people living at home but might be effective when restricted to subjects with poor health.

\section{Introduction}

In view of the aging population preventive programmes are being developed which aim to enhance the independent functioning of elderly people. Instead of medical screening for specific diseases (which seems to be disadvantageous) regular assessment of the functional abilities of elderly people has been advocated. ${ }^{12}$ Regular visits by health visitors or public health nurses reflect such an approach. Through repeated assessment of the functional abilities and professional advice it is hoped that elderly people will have better health and that admissions to institutional care will be reduced.

In the early 1980s two controlled experiments showed results that only partly agreed with this assumption. One was performed in Denmark among 600 elderly people aged 75 years or over. ${ }^{3}$ An intervention group was visited four times a year for three years whereas the control group received no home visits. The study showed promising results: the home visits reduced the number of admissions to hospitals and nursing homes, the medical care costs per subject, and mortality. The other experiment was performed in a rural and an urban area in Wales. In both areas 600 elderly people (aged 70 or over) were selected. The intervention groups received at least two visits in two years and the control groups received no home visits. ${ }^{45}$ The results were only partly consistent: mortality was reduced only in the urban area and functional state only in the rural area. The subjective view of life seemed to have improved throughout. The study reported no differences in the use of institutional care.

As the evidence of the usefulness of home visits was promising, though not entirely convincing, we decided to perform a new experiment in the Netherlands. ${ }^{6}$ The study was conducted in Weert (60000 inhabitants) and investigated the effects of the visits on the health state of and use of services by elderly people.

\section{Methods}

STUDY POPULATION AND RANDOMISATION

To select participants for the experiment and to obtain background information on their health state and use of some services, a postal questionnaire was sent out to all 1545 subjects in the area aged $75-84$ years who were living at home. Subjects and their partners who were already receiving home nursing care on a regular basis were excluded from the study to avoid the effects of other nursing care beforehand.

The questionnaire dealt with the admission criteria as well as relevant prognostic criteria, such as self rated health, functional state, informal support, and use of services. Informed consent of the subjects was obtained on a separate page of the questionnaire.

The response rate was $85 \%$ (1285). Of these respondents, 1182 were willing to participate in the study. After exclusion of the 126 subjects and their partners who were already receiving home nursing care and 20 subjects who lived in a monastery, a sample of 580 (out of 1036) subjects formed the study population.

These participants were stratified before random allocation on sex, self rated health, composition of household, and social class (neighbourhood). Randomisation was performed within each stratum by means of random numbers generated by computer. Participants who were living together were always allocated to the same group. Subjects who had been allocated to the intervention group were then randomly assigned to one of the visiting nurses. Seven people who had been allocated to the intervention group refused the home visits after randomisation.

\section{INTERVENTIONS}

The intervention group (292) was visited four times a year over a period of three years with extra visits if necessary. Ninety six subjects received 174 extra visits. Subjects in the intervention group could also contact

Correspondence to:

Dr van Rossum. 
the nurse by telephone every day to discuss problems or to ask for an extra visit. Each participant was visited by the same nurse during the entire intervention period, and if subjects became institutionalised the visits continued as before. The nurses had already been working in home nursing care for many years and were employed specifically for the study.

In general, the visits lasted 45 to 60 minutes. During the visits no physical examinations were performed. The nurses discussed health topics in a broad sense with the participants and gave information and advice. If necessary, subjects were advised to contact other services. This advice was given to half of the subjects (154); 111 of the 290 referrals were to a general practitioner. To standardise the intervention the nurses used a checklist containing questions on, for instance, functional state, medication, social contacts, and housing conditions. Additional guidelines were developed to enable them to discuss the various health topics more systematically and to probe for underlying problems. Details of the visits have been published elsewhere. ${ }^{7}$

The 288 subjects in the control group received no home visits. They could, however, use or apply for all the regular services in the area as before. To ensure that the control group would not receive similar interventions to the intervention group, the nurses of the home nursing care organisation in the research area paid no unsolicited visits to the participants during the study.

\section{FOLLOW UP AND OUTCOME MEASURES}

To trace the effects of the home visits on health state the initial postal questionnaire was sent out again after one and a half years and at the end of the intervention period. The response on both measurements (among 528 and 493 subjects still alive, respectively) was $97 \%$. Shortly after the last postal measurement all subjects (two had died in the meantime) were contacted for a personal interview; 453 subjects (92\%) participated. The interviews were conducted by trained interviewers, who were unaware of whether a participant had been regularly visited by a nurse or not. Biased outcomes were also prevented by including subjects still living at home as well as those who were institutionalised during the intervention period in all follow up measurements.

Primary outcome measures for health state were self rated health, well being, and the functional and mental state. The final interviews also included questions on, among other things, existing health complaints and hearing and sight problems. Mortality was registered in both groups, although we considered improving the quality rather than the duration of life a more important goal of the intervention. To measure self rated health the participants were asked to rate their health between 0 (poor health) and 10 points (excellent health). The same rating scale is used in the Dutch educational system to mark papers. Scores between $0-5,6-7$, or 8-10 correspond with poor, fair, and good or excellent health, respectively. With respect to functional state five questions were asked on activities of daily living and five questions on household tasks. Scores were computed between 0 (no disabilities) and 5 points (completely dependent). Self rated health and functional state were recorded at baseline and during all follow up measurements. Other primary outcome measures such as well being and indicators of mental state were measured only during the final interviews. Because there was some overlap between the items of the various scales we constructed abbreviated versions of some scales on the basis of data gathered in a comparable population of elderly people living at home. ${ }^{8}$ As regards depressive complaints, four items of the original 20 items of Zung's self rating depression scale $^{9}$ were selected and five items of the abbreviated mental test to measure memory disturbances..$^{10}$ Lone- liness and well being were measured by using two Dutch scales, ${ }^{11} 12$ in which well being was restricted to two aspects (morale and optimism).

Information on the use of community and institutional care was gathered concurrently by the services during the three year period. The organisations were not informed whether participants were receiving preventive home visits or not. Because five of the 31 general practitioners in the area did not participate in the study information about the contact rate with the general practitioner and referrals to outpatient clinics was restricted to $493(85 \%)$ participants. Data on the use of physiotherapy were gathered with the help of the sick funds health insurance scheme, which covered 419 $(72 \%)$ participants. To see whether the visits reduced expenditure we calculated for each group the costs of service use during the intervention period. The calculation was restricted to the health related costs; other costs, such as additional pensions as a result of (possibly) decreased mortality were not taken into account. In the calculation we used the average total costs per service, which included both the variable costs and the fixed (or overhead) costs.

\section{DATA ANALYSIS}

During the intervention period no separate analyses were performed for the two groups to prevent the researchers and nurses from influencing the intervention process by knowing interim results. Analyses were performed on the basis of a protocol and according to the intention to treat principle.

For the health related outcome measures recorded at baseline and during follow up (self rated health and functional state) the groups were compared for differences in their mean scores at follow up and their mean improvement or deterioration scores. With regard to outcome measures for which baseline information was lacking, only differences between the two groups in the scores after three years could be calculated. With respect to the use of services, the proportions of users in each group were compared for each service separately. In addition, we calculated the differences between the groups regarding the average frequency and duration of service use per person.

One way analysis of covariance was used to adjust the estimated differences in outcomes for small prognostic differences between the two groups at the start of the experiment. This adjustment did not change the estimates (or their confidence intervals) of the group differences. Hence we present only the unadjusted estimates with their $90 \%$ confidence intervals. Finally, survival analyses were performed on the mortality data by using Cox's proportional hazards model.

\section{Results}

COMPARABILITY AT BASELINE

At the start of the study the distribution of the prognostic variables measured was almost equal for the two groups (table I). Apart from the characteristics on which the participants had been stratified before randomisation, there were no differences regarding age, recent contacts with the general practitioner, availability of social support, or social contacts. There were only some small differences (in favour of the intervention group) with regard to functional state.

\section{HEALTH STATE}

Mortality - Table II shows that no substantial differences in mortality were found between the two groups. The rates were similar after one and two years $(6 \%$ and $11 \%$, respectively). After three years 42 subjects (14\%) in the intervention group had died compared to 50 $(17 \%)$ in the control group. Not surprisingly, further analysis of the data by using Cox's proportional 
hazards model showed that subjects in the control group had only a slightly increased risk of mortality. The hazard ratio, which can be interpreted as a relative risk, was $1.2(90 \%$ confidence interval 0.9 to $1 \cdot 7)$. Considering the small overall differences between the two groups mortality is unlikely to have influenced the results on the other outcome measures.

Self rated health-Table III shows the average scores on self rated health for the two groups at the start of the study, after one and a half years, and after three years. The mean change in score over time for each group is also shown. It was calculated for each participant by subtracting the baseline score from the scores on the postal questionnaires halfway through and at the end of the study. A similar calculation for the interview score and baseline score was not performed because the two scores were obtained by using different methods of data collection. We could find hardly any differences in self rated health between the two groups. On the scale of 0 to 10 the visited group scored only 0.1 point better than the control group, both after one and a half years and at the end of the study. Similar results were seen when the changes in scores over time were considered. Halfway through and at the end of the study we also

TABLE I-Distribution of baseline characteristics among elderly people who received home visits (intervention group) and those who did not (control group). Figures are numbers (percentages) of subjects

\begin{tabular}{lrr}
\hline & $\begin{array}{c}\text { Intervention } \\
\text { group } \\
(\mathrm{n}=292)\end{array}$ & $\begin{array}{c}\text { Control } \\
\text { group } \\
(\mathrm{n}=288)\end{array}$ \\
Characteristic & $122(42)$ & $123(43)$ \\
\hline Men & $170(58)$ & $165(57)$ \\
Women & & \\
Age (years): & $210(72)$ & $211(73)$ \\
$\quad 75-79$ & $82(28)$ & $77(27)$ \\
$80-84$ & & \\
Composition of household: & $113(39)$ & $111(39)$ \\
Along & $179(61)$ & $177(62)$ \\
Together & & \\
Self rated health: & $57(20)$ & $53(18)$ \\
$0-5$ & $105(36)$ & $105(37)$ \\
$6-7$ & $130(45)$ & $130(45)$ \\
$8-10$ & & \\
Functional state & & \\
Activities of daily living disabilities & $257(91)$ & $245(86)$ \\
0 & $27(10)$ & $41(14)$ \\
$1-5$ & & \\
Household disabilities & $107(38)$ & $95(35)$ \\
0 & $112(39)$ & $107(39)$ \\
$1-2$ & $65(23)$ & $73(27)$ \\
$3-5$ & & \\
Informal care available (if necessary): & $246(86)$ & $249(88)$ \\
Yes & $39(14)$ & $35(12)$ \\
No & & \\
Contacts with general practitioner in past 3 months: & $151(54)$ & $155(56)$ \\
$0-1$ & $129(46)$ & $122(44)$ \\
$>1$ & &
\end{tabular}

*With regard to activities of daily living, five questions were asked relating to use of stairs, bathing, dressing, rising from bed, and toileting. As regards household activities, five questions were asked relating to shopping, household activities, five questions were asked relating to shopping,
cooking, laundering, making beds, and mopping/washing windows. For both activities of daily living and household activities scores were computed both activities of daily living and household activities scores
ranging from 0 (no disabilities) to 5 (completely dependent).

TABLE II-Cumulative mortality in elderly people who received home visits (intervention group) and those who did not (control group) over three years. Figures are numbers (percentages) of subjects

\begin{tabular}{lcc}
\hline Year & Intervention group $(\mathrm{n}=292)$ & Control group $(\mathrm{n}=288)$ \\
\hline 1 & $15(5)$ & $16(6)$ \\
2 & $33(11)$ & $32(11)$ \\
3 & $42(14)$ & $50(17)$ \\
\hline
\end{tabular}

TABLE III-Mean scores and mean changes in scores on self rated health in elderly people who received home visits (intervention group) and those who did not (control group)

\begin{tabular}{|c|c|c|c|c|c|c|}
\hline \multirow[b]{2}{*}{$\begin{array}{l}\text { Time of } \\
\text { assessment }\end{array}$} & \multicolumn{3}{|c|}{ Mean scores } & \multicolumn{3}{|c|}{ Mean changes in scores } \\
\hline & $\begin{array}{l}\text { Intervention } \\
\text { group }\end{array}$ & $\begin{array}{l}\text { Control } \\
\text { group }\end{array}$ & $\begin{array}{c}\text { Difference } \\
(90 \% \text { confidence } \\
\text { interval })\end{array}$ & $\begin{array}{l}\text { Intervention } \\
\text { group }\end{array}$ & $\begin{array}{l}\text { Control } \\
\text { group }\end{array}$ & $\begin{array}{c}\text { Difference } \\
\text { (90\% confidence } \\
\text { interval) }\end{array}$ \\
\hline $\begin{array}{l}\text { Start } \\
1.5 \text { Years } \\
3 \text { Years } \\
3 \text { Years }\end{array}$ & $\begin{array}{l}7 \cdot 2 \\
7 \cdot 2 \\
6 \cdot 9 \\
7 \cdot 0\end{array}$ & $\begin{array}{l}7 \cdot 2 \\
7 \cdot 1 \\
6 \cdot 8 \\
7 \cdot 1\end{array}$ & $\begin{array}{r}0.0(-0.2 \text { to } 0.2) \\
0.1(-0.2 \text { to } 0.4) \\
0.1(-0.2 \text { to } 0.4) \\
-0.1(-0.2 \text { to } 0.4)\end{array}$ & $\begin{array}{l}-0 \cdot 2 \\
-0 \cdot 4\end{array}$ & $\begin{array}{l}-0.3 \\
-0.6\end{array}$ & $\begin{array}{l}0.1(-0.1 \text { to } 0.3) \\
0.2(-0.1 \text { to } 0.5)\end{array}$ \\
\hline
\end{tabular}

asked the participants whether in their opinion their health state had improved or deteriorated compared to the start of the study. No differences between the two groups were found in this respect.

Functional state data were analysed in the same way (table IV). The differences in scores in table IV refer to the intervention group. A negative difference means that the visited group had a lower and thus a more favourable score compared to the control group. A positive difference on the other hand indicates a better score for the control group. No differences were found in favour of the intervention group. Because the score for activities of daily living is a well known but not very sensitive measure of functional state for intervention studies among elderly people living at home the final interview also inquired about some other, physically more difficult activities (walking outside for 15 minutes, cycling, and tending the garden). The two groups did not differ with regard to these more complex activities either. The interviews also included questions on existing health complaints over the past six months (headaches, shortness of breath, fatigue, and irritability). Additional questions dealt with falls during the past six months and problems of equilibrium, sleeping, hearing, and sight. We found no differences between the two groups with respect to these health aspects.

Well being and mental state-No large differences were found with respect to well being and mental state. The intervention group scored slightly lower on morale and somewhat better on optimism than the control group. Overall, however, no favourable effects of the intervention were found. Also we did not find differences between the groups with respect to loneliness, depressive complaints, or memory problems.

\section{USE OF SERVICES}

Community care-Table $\mathrm{V}$ shows the use of various community care services in the two groups. The average frequency of use was calculated per person at baseline, whether the subjects had or had not used the specific service (292 in the intervention group and 288 in the control group). In general, the use of community care had increased in the intervention group. More visited subjects had received home help and home nursing care, whereas the proportions of users were similar for meals on wheels and physiotherapy. The large differences in the frequency of use of home helps and meals on wheels could largely be attributed to those subjects in the intervention group who already profited from these services at the start of the study. Nearly all subjects in both groups contacted their general practitioner at least once. The contact rates, in which no distinction could be made between emergency calls and regular contacts, were similar for the two groups. The general practitioners also registered referrals to outpatient clinics. During the intervention period fewer subjects in the intervention group were referred: $55 \%$ versus $66 \%(90 \%$ confidence interval for difference $4 \%$ to $18 \%$ ). This difference had already emerged in the first year and thereafter remained constant for the rest of the intervention period. ${ }^{7}$ As for the frequency of referrals no differences between the groups were found.

Institutional care-There was a small difference between the groups in admissions to hospital: $41 \%$ of the intervention group versus $46 \%$ of the control group ( $90 \%$ confidence interval for difference $-2 \%$ to $12 \%$ ). The difference occurred in the first year, while the second and third intervention years did not add to this difference (table VI). A difference was also found for the number of hospital days. It was already present in the first year and rose to 3.5 days per person after three years $(-0.7$ to $7 \cdot 9)$. The average number of hospital days per admission was the same for both groups 
TABLE IV-Mean scores* and mean changes in scores on functional state (activities of daily living and household disabilities) in elderly people who received home visits (intervention group) and those who did not (control group)

\begin{tabular}{|c|c|c|c|c|c|c|}
\hline \multirow[b]{2}{*}{$\begin{array}{l}\text { Time of } \\
\text { assessment }\end{array}$} & \multicolumn{3}{|c|}{ Mean scores } & \multicolumn{3}{|c|}{ Mean changes in scores } \\
\hline & $\begin{array}{l}\text { Intervention } \\
\text { group }\end{array}$ & $\begin{array}{l}\text { Control } \\
\text { group }\end{array}$ & $\begin{array}{c}\text { Difference } \\
\text { (90\% confidence } \\
\text { interval })\end{array}$ & $\begin{array}{l}\text { Intervention } \\
\text { group }\end{array}$ & $\begin{array}{l}\text { Control } \\
\text { group }\end{array}$ & $\begin{array}{c}\text { Difference } \\
\text { (90\% confidence } \\
\text { interval) }\end{array}$ \\
\hline \multicolumn{7}{|c|}{ Disabilities on activities of daily living } \\
\hline Start & $0 \cdot 1$ & 0.2 & $-0.1(0.0$ to 0.2$)$ & & & \\
\hline 1.5 Years & 0.3 & 0.3 & $0.0(-0.1$ to 0.1$)$ & $0 \cdot 2$ & $0 \cdot 2$ & $0.0(-0.1$ to 0.1$)$ \\
\hline 3 Years & 0.6 & 0.5 & $0.1(0.0$ to 0.2$)$ & 0.4 & $0 \cdot 3$ & $0.1(0.0$ to 0.2$)$ \\
\hline 3 years $\dagger$ & 0.5 & $0 \cdot 5$ & $0 \cdot 0(-0 \cdot 2$ to $0 \cdot 2)$ & & & \\
\hline \multicolumn{7}{|c|}{ Household disabilities } \\
\hline Start & 1.5 & 1.6 & $-0.1(-0.1$ to 0.3$)$ & & & \\
\hline 1.5 Years & $2 \cdot 0$ & $2 \cdot 0$ & $0.0(-0.3$ to 0.3$)$ & 0.6 & 0.4 & $0.2(0.0$ to 0.4$)$ \\
\hline 3 Years & $2 \cdot 2$ & $2 \cdot 3$ & $-0.1(-0.2$ to 0.4$)$ & 0.8 & 0.7 & $0.1(-0.1$ to 0.3$)$ \\
\hline 3 yearst & $2 \cdot 0$ & $2 \cdot 0$ & $0.0(-0.3$ to 0.3$)$ & & & \\
\hline
\end{tabular}

TABLE V-Use of community services in elderly people who received home visits (intervention group) and those who did not (control group)

\begin{tabular}{|c|c|c|c|c|c|}
\hline \multirow[b]{2}{*}{ Service } & \multirow[b]{2}{*}{$\begin{array}{l}\text { Time of } \\
\text { assessment }\end{array}$} & \multicolumn{2}{|c|}{$\begin{array}{l}\text { Intervention group } \\
(\mathrm{n}=292)\end{array}$} & \multicolumn{2}{|c|}{$\begin{array}{c}\text { Control group } \\
(n=288)\end{array}$} \\
\hline & & $\begin{array}{l}\text { No }(\%) \\
\text { of users }\end{array}$ & $\begin{array}{l}\text { Frequency } \\
\text { of use (mean) }\end{array}$ & $\begin{array}{l}\text { No }(\%) \\
\text { of users }\end{array}$ & $\begin{array}{c}\text { Frequency } \\
\text { of use (mean) }\end{array}$ \\
\hline Home help (hours) & Start & $53(18)$ & & $52(18)$ & \\
\hline Home nursing (contacts) & Start & - & -1000 & - & - \\
\hline Meals on wheels (meals) & $\begin{array}{l}3 \text { Years } \\
\text { Start }\end{array}$ & $\begin{array}{c}131(45) \\
12(4)\end{array}$ & $3779(13)$ & $\begin{array}{c}108(38) \\
8(3)\end{array}$ & $3947(14)$ \\
\hline & $\begin{array}{l}3 \text { Years } \\
\text { Start }\end{array}$ & $\begin{array}{c}36(12) \\
2(0 \cdot 7)\end{array}$ & $15650(54)$ & $33(12)$ & 9224 (32) \\
\hline $\begin{array}{l}\text { Ambulatory mental health care } \\
\text { (contacts) }\end{array}$ & $\begin{array}{l}\text { Start } \\
\text { 3 Years }\end{array}$ & $\begin{array}{l}2(0 \cdot 7) \\
17(6)\end{array}$ & $175(0.6)$ & $\begin{array}{r}3(1) \\
10(4)\end{array}$ & $127(0 \cdot 4)$ \\
\hline $\begin{array}{l}\text { Physiotherapy (contacts) } \\
\text { General practitionert: }\end{array}$ & 3 Years & $66(31)$ & $2371(12)$ & $65(31)$ & $1661(8)$ \\
\hline $\begin{array}{l}\text { Contacts } \\
\text { Referrals to outpatient clinic }\end{array}$ & $\begin{array}{l}3 \text { Years } \\
\text { Start } \\
3 \text { Years }\end{array}$ & $\begin{array}{r}230(96) \\
90(38) \\
132(55)\end{array}$ & $\begin{array}{c}4185(17) \\
130(0.5) \\
333(1.4)\end{array}$ & $\begin{array}{r}246(97) \\
98(39) \\
166(66)\end{array}$ & $\begin{array}{r}4431(18) \\
137(0.5) \\
381(1.5)\end{array}$ \\
\hline
\end{tabular}

* Registration of contacts with physiotherapists related to 207 subjects in intervention group and 212 subjects in control group.

†Complete records available for 240 subjects in intervention group and 253 subjects in control group.

TABLE VI-Cumulative numbers of hospital admissions and hospital days in elderly people who received home visits (intervention group) and those who did not (control group)

\begin{tabular}{|c|c|c|c|c|c|c|}
\hline \multirow[b]{2}{*}{ Year } & \multicolumn{3}{|c|}{ Intervention group $(n=292)$} & \multicolumn{3}{|c|}{ Control group $(n=288)$} \\
\hline & $\begin{array}{l}\text { No (\%) of } \\
\text { subjects }\end{array}$ & Admissions & $\begin{array}{l}\text { Days in } \\
\text { hospital }\end{array}$ & $\begin{array}{l}\text { No (\%) of } \\
\text { subjects }\end{array}$ & Admissions & $\begin{array}{l}\text { Days in } \\
\text { hospital }\end{array}$ \\
\hline 1 Year & $45(15)$ & 59 & 1318 & $64(22)$ & 88 & 2189 \\
\hline 2 Years & $88(30)$ & 131 & 2971 & $108(38)$ & 188 & 3603 \\
\hline 3 Years & $121(41)$ & 189 & 3838 & $133(46)$ & 253 & 4789 \\
\hline \multicolumn{7}{|l|}{ Over three years: } \\
\hline Per user & & 1.6 & $31 \cdot 7$ & & 1.9 & $36 \cdot 0$ \\
\hline Per admission & & & $20 \cdot 3$ & & & $18 \cdot 9$ \\
\hline Per person difference $(90 \%$ & & & & & & \\
\hline confidence interval) & & $0 \cdot 6$ & $13 \cdot 1$ & & 0.9 & $\begin{array}{l}16.6 \\
3.5(-0.7 \text { to } 7.9)\end{array}$ \\
\hline
\end{tabular}

(about 20 days on average). We then studied differences in the (re)admission rate, adjusting for differences in baseline characteristics and mortality. Because of missing admission and discharge dates for several admissions (all of which took place outside the research area), calculation of the risks by using Cox's proportional hazards model resulted in imprecise estimates. As an alternative, the incidence density rate was calculated for each group by dividing the number of admissions by the total number of days the subjects were at risk of being admitted to the hospital (the number of days a subject was alive minus the days spent in the hospital). The ratio of the two rates or the incidence rate ratio was $1.4(1.2$ to 1.6$)$, which indicates that subjects in the control group had a $40 \%$ increased risk of being admitted to the hospital. No difference was found in admissions to homes for the elderly, which provide sheltered residential accommodation. Twenty subjects in the intervention group (7\%) compared to 18 in the control group (6\%) were admitted to these homes. In all, the visited subjects spent 284 months (or 1 month per person of the total group) in homes for the elderly. These figures were 241 months (or 0.8 months per person) for the control group. We also found no differences with respect to admissions to nursing homes: seven subjects in the intervention group ( $2 \%)$ spent 48 months in nursing homes, whereas five subjects in the control group (2\%) spent 54 months in nursing homes.

\section{HEALTH SERVICES EXPENDITURE}

Table VII shows that the visits were not financially beneficial: the expenditures on service use per person in the intervention group exceeded those in the control group by $4 \%$. Apart from the reduced hospital costs, the gains in favour of the intervention group were only marginal (home nursing care and nursing home); the increased costs in the intervention group with respect to most community services and homes for the elderly balanced the reduction in hospital costs.

\section{EFFECTS IN SUBGROUP WITH POOR HEALTH}

In addition to the effects of the home visits for the study population in general we explored whether particular subgroups of the population benefited from the visits. Subgroups were formed according to age (75-79 or 80-84), sex, composition of household (living along or with others), disabilities in performing household tasks (none; one or two; three to five), and self rated health (scores between $0-5$, or $6-7$, or $8-10$ ). Within these subgroups separate analyses were performed for both groups.

Convincing differences were found only in the subgroup who rated their health as poor at baseline (scores $0-5$, mean score $4 \cdot 7$ ). This subgroup consisted of 57 subjects in the intervention group and 53 subjects in the control group. These visited participants scored considerably better on self rated health and the performance of household activities after one and a half and three years, and, to a lesser extent, they scored more favourably on depressive complaints and memory disturbances. Furthermore, fewer subjects in the intervention group had died (14 versus 22 of the control group). As regards the use of services the differences within this subgroup in the use of community care were more striking than among the total groups, and fewer subjects were referred to outpatient clinics (27 of the intervention group versus 38 of the control group). Large effects on hospital admissions were found: the visited subjects spent 1134 days or 20 days per person in the hospital compared to 2043 or 39 days per person in the control group. Thus, almost the entire difference in number of hospital days for the total groups emerged within this small subgroup. On the other hand, more visited subjects in this subgroup were admitted to homes for the elderly (12 versus seven) whereas no differences were found as regards admissions to nursing homes.

The results for the total groups showed that differences in referrals to outpatient clinics and hospital admissions had already emerged during the first year.

TABLE VII-Health services expenditure in elderly people who received home visits (intervention group) and those who did not (control group) (Dutch guilders*)

\begin{tabular}{lrrc}
\hline Service & $\begin{array}{c}\text { Intervention } \\
\text { group }\end{array}$ & $\begin{array}{c}\text { Control } \\
\text { group }\end{array}$ & $\begin{array}{c}\text { Difference per } \\
\text { person (\%) }\end{array}$ \\
\hline Community care services & 2530724 & 2209147 & +13 \\
Hospital† & 1919000 & 2394500 & -21 \\
Long term institutional care & 1019532 & 960693 & +5 \\
Home visits & 393981 & & \\
\hline Total & 5863237 & 5564340 & \\
Per person & 20080 & 19321 & +4 \\
\hline
\end{tabular}

* During intervention period, exchange rate for 1 Dutch guilder was about $£ 0.29$ and $\$ 0.51$

†Only referrals by general practitioner to outpatient clinics were registered. As information on subsequent frequency of contacts with clinicians is lacking, expenditures on outpatient clinics were omitted from calculation. $\ddagger$ Expenses of home visits include average time spent by three nurses in travelling, preparing visits, and administration. 
As a large part of the overall differences for both services occurred among the small subgroup of subjects who perceived their health as poor at baseline, we studied the data on referrals and admissions over time separately for those who rated their health as poor (scores 0-5) and for those who were more positive about their health (scores 6-10) at the start of the study. Particularly with respect to hospital admissions, differences in favour of subjects with poor health were gained from the start of the experiment, whereas no differences appeared among the healthier subjects.

\section{Discussion}

The rationale behind preventive home visits is that it is useful to trace subjects who have no contact with the home nursing care organisation. Once traced repeated assessment of general functional abilities followed by professional advice and effective referral to other services is thought to enhance the independent functioning of elderly people. Our results do not confirm these presumed benefits.

No effects could be detected on health in terms of physical and mental state and more general measures of health and well being. Although the visits increased the use of community care to some extent, they did not substantially reduce the use of institutional care. Some beneficial effects were found for more specialised forms of care (referral to outpatient clinics and hospital admissions), but the differences were not very large per person over the three years. The reduction of days spent in hospital, for instance, as little as one day per person per year. No reduction of long term institutional care was found (nursing homes and homes for the elderly), and the health care expenditures per person had slightly increased in the intervention group.

The question, of course, is why we could not show more substantial effects. The most convincing explanation is that the general population of elderly people is "too healthy" to gain benefit. Moreover, there is a fairly extensive health care system for the elderly available. Both factors seem to make it difficult for the preventive home visits to have a surplus value for subjects whose health state is already fairly good.

There might, however, have been positive effects which we could not detect. Our measurements on the health state may not have been sensitive enough to show relevant effects. No substantial differences between the two groups were found, however, whether the outcomes were measured by means of postal questionnaires or during personal interviews, and whether we used a more elaborate index or a direct question to measure the outcome.

Another explanation could be that the effects differed among the three nurses, which masked overall differences. However, we could not find any differences in outcomes among the three groups of visited subjects. Intervention effects might have also influenced the results. Elderly people in the visited group had regular discussions about their health, and as a result they may have expressed their health problems more easily than the non-visited subjects. This might have led to relatively poorer scores in the visited group, making existing differences in health disappear. Finally, the number of visits per year (at least four) or the duration of the intervention period (three years) may have been insufficient to show beneficial effects.

Although the overall results are not positive, they agree partly with the results of previous studies among elderly people. The experiment in Wales showed slightly positive effects, but the differences were not very convincing. ${ }^{4} \mathrm{~A}$ new controlled study by the Welsh research team also showed no beneficial effects, although they merely reported on the effects of the visits on the incidence of fractures. ${ }^{13}$ Other controlled

\section{Practice implications}

- Regular assessment of the functional abilities of elderly people living at home has been claimed to improve health and reduce the use of institutional care

- This study shows no convincing evidence for this assumption for the general population of elderly people

- Regular assessment seems to be effective, however, when restricted to those elderly people with poor health

experiments in which the general population was screened by a public health nurse or general practitioner and followed up by a primary care team also reported hardly any positive effects. ${ }^{14} 15$

The results of the Danish study with respect to the use of services and mortality were more convincing than the data reported here. ${ }^{3}$ Although their results on the effects on health state were not published, the researchers told us that they had found no differences in this respect. We do not know exactly what caused the discrepancy in results. Possibly our study population had better health at the start of the study. This may have been caused partly by our decision to exclude from the study people who were already receiving regular home nursing care. Also, in comparison with other western countries a fairly large proportion of old people in the Netherlands live in institutions (about $7 \%$ of those aged 65 or over live in homes for the elderly and $2.5 \%$ in nursing homes). ${ }^{16} 17$ Finally, the two groups in Denmark may not have been prognostically comparable at baseline, despite randomisation. Despite the findings in the Danish study, we consider our results and the available evidence from other studies not convincing enough to encourage the use of preventive home visits among the general population of elderly people.

Additional analyses showed that the visits seemed to have been effective for subjects with initially poor health. These results are promising and in line with two recently published controlled studies. ${ }^{1819}$ The available evidence has limitations, however, such as the small numbers of subjects with poor health included in our study. Supporting evidence is therefore needed from new studies among subjects with poor health.

Our findings may contribute to the debate on the usefulness of preventive programmes for the elderly. ${ }^{20-22}$ If it is true that assessment and follow up programmes are useful only for subjects with poor health a revision of the programme is needed. Regular attention does not prevent future health problems among old people but, on the contrary, benefits can be gained only when health problems are already present. This reduces the target population, and scarce resources should be allocated to those for whom special attention is useful.

This study was supported by grants from the Netherlands Ministry of Welfare, Health and Cultural Affairs, the Foundation for Research and Development of Social Health Care (STOOM), and Het Praeventiefonds.

We thank Roos Dekkers-Beemer, José Moonen-Strous, and Leny Snellen, who visited the elderly subjects, and Winnie van Oorschot-van de Sande, who assisted in collecting and analysing the data. Jeanette Kil-van Lierop and Anton Mantel played an important part in preparing and introducing the study in the research area. Alexander Volovics (department of medical informatics and statistics) and Alphons G H Kessels (department of epidemiology) gave advice on the data analysis. Richard Janssen (department of health care economics) advised us on the calculation of the health care expenditures. 
1 Buckley EG, Williamson J. What sort of "health checks" for older people? BMF 1988;296:1144-5.

Frederiks CMA. Preventief geneeskundig onderzoek bij ouderen: pro's en contra's. Tijdschr Gerontol Geriatr 1986;17:205-8.

3 Hendriksen C, Lund E, Stromgärd E. Consequences of assessment and intervention among elderly: a three year randomised controlled trial. $B M$ 1984;289:1522-4.

4 Vetter NJ, Jones DA, Victor CR. Effect of health visitors working with elderly patients in general practice: a randomised controlled trial. $B M \mathcal{F}$ 1984;288: patients $369-72$.

5 Vetter NJ, Jones DA, Victor CR. The effectiveness of health visitors working with the elderly. Final report. Vol 1. Cardiff: Welsh National School of Medicine, 1984.

6 Rossum E van, Frederiks C, Philipsen H, Kil-van Lierop J, Mantel A Portengen J, et al. Design of a Dutch study to test preventive home visits to the elderly. Nurs Res 1991;40:185-8.

7 Rossum E van. Effects of preventive home visits to the elderly. Datawyse: Maastricht, 1993. (PhD thesis.)

8 Frederiks CMA, Wierik MJM te, Rossum HJL van, Visser APh, Volovics A Sturmans F. Why do elderly people seek professional care? Methodologies compared. I Community Health 1992;17:131-4

9 Zung WWK. A self rating depression scale. Arch Gen Psychiatry 1965;12: 63-70.

10 Qureshi KN, Hodkinson HM. Evaluation of a ten-question mental test in the institutionalized elderly. Age Ageing 1974;3:152-7.

11 Jong-Gierveld J de, Kamphuis FH. The development of a Rasch-type loneliness scale. Applied Psychological Measurement 1985;9:289-99.
12 Templeman CJJ. Welbevinden bij ouderen. Konstruktie van een meet instrument. Groningen: University of Groningen, 1987:56-82. ( $\mathrm{PhD}$ thesis.) 13 Vetter NJ, Lewis PA, Ford D. Can health visitors prevent fractures in elderly people? $B M \mathcal{F}$ 1992;304:888-90

14 Tulloch AJ, Moore V. A randomized controlled trial of geriatric screening and surveillance in general practice. $\mathcal{F} R$ Coll Gen Pract 1979;29:733-42.

15 McEwan RT, Davison N, Forster DP, Pearson P, Stirling E. Screening elderly people in primary care: a randomized controlled trial. British fournal of General Practice 1990;40:94-7.

16 CBS. Statistisch jaarboek 1992. Den Haag: SDU/uitgeverij, CBS-publikaties 1992.

17 SIG faarboek verpleeghuizen 1990. Utrech: SIG, 1991.

18 Hall N, De Beck P, Johnson D, Mackinnon K. Gutman G, Glick N. Randomized trial of a health promotion program for frail elders. Canadian fourmal of Aging 1992;11:72-91.

19 Pathey MSJ, Bayer A, Harding K, Dibble A. Randomised trial of case finding and surveillance of elderly people at home. Lancet 1992;340:890-3.

20 Harris A. Health checks for people over 75 . The doubts persist. $B M$ 1992;305:599-600.

21 Tremellen J. Assessment of patients aged over 75 in general practice. $B M$ 1992;305:621-4.

22 Brown K, Williams EI, Groom L. Health checks on patients 75 years and over in Nottinghamshire after the new GP contract. BM7 1992;305:61 9-21.

(Accepted 15 April 1993)

\title{
Accuracy of diagnosis of psychosis on general practice computer system
}

\author{
Irwin Nazareth, Michael King, Andrew Haines, Luiza Rangel, Sara Myers
}

\begin{abstract}
Objectives-To determine the accuracy of diagnoses of schizophrenia and non-affective psychosis entered by general practitioners on a computer system. To compare recording of clinical events on computer with written records.
\end{abstract}

Design-Examination of case notes of all patients with a computer diagnosis of psychosis. Search of 8000 randomly selected patient records to identify patients with psychosis not recorded on computer and comparison of 141 computer and written entries for prescribing and consultation in each practice.

Setting-13 London practices on the VAMP research bank.

Main outcome measures-Accuracy of record of psychosis compared with ICD 9, American Psychiatric Association diagnostic manual, and syndrome checklist criteria.

Results-Computer search revealed 102 patients with schizophrenia, 78 with other psychoses, and 71 with non-affective psychosis who had adequate case notes. The sensitivity and positive predictive value of the computer diagnosis of schizophrenia were $88 \%(95 \%$ confidence interval $62 \%$ to $98 \%)$ and $71 \%$ $(48 \%$ to $88 \%)$. For all non-organic psychoses sensitivity was $91 \%(74 \%$ to $97 \%)$ and positive predictive value was $91 \%(74 \%$ to $98 \%)$. On average $95 \%$ of all known prescriptions and $74 \%$ of all consultations were recorded on computer compared with $42 \%$ and $75 \%$ in written records.

Conclusions-Recording of psychotic illness on the VAMP computer is accurate and complete. Prescribing was more fully recorded on the computer than on the written records. Computer databases of well motivated general practitioners could be used for research.

\section{Introduction}

The proportion of general practices with computerised records in the United Kingdom has increased from a quarter in $1989^{1}$ to about two thirds in $1991 .^{2}$ About a third of general practices use the VAMP computer systems, which were offered to general practitioners without charge between 1987 and 1991 provided they entered data according to specified guidelines. ${ }^{3}$ The information to be recorded included demographic information, medical diagnoses, all prescriptions issued, and an indication for any newly prescribed drug. After the general practitioners had received instruction over 10-12 months the quality of the information recorded on the computer was examined. Until March 1991 practices were able to retain their computers at no cost if their data were at least $90 \%$ complete and accurate. ${ }^{4}$

After a practice has been recruited on to the VAMP research bank, the accuracy of the recorded information is monitored regularly by the company. Recent estimates suggest that data recorded by one in three VAMP practices are of research standard.' Since March 1991 computers have not been available at no cost, although practices are offered a share in the company profits. A few practices, however, provide data without any financial benefits. Practices using the VAMP system are representative of those nationwide with respect to practice profile and age and sex distribution of patients and general practitioners. Patterns of morbidity are also broadly representative. ${ }^{67}$

Although the potential of computerised information systems in large epidemiological studies has been recognised, ${ }^{8}$ doubts have been raised about the quality of data entered. ${ }^{9}$ A study comparing clinical diagnoses written in letters received from hospital consultants with diagnoses entered on computer suggested that the information was satisfactory for most clinical studies, but the diagnoses recorded by the general practitioners were not independently verified.

We conducted a study to determine the accuracy (sensitivity, specificity, and predictive value) of diagnoses for schizophrenia and non-affective psychosis entered by the general practitioners on the VAMP computers and to compare the level of recording of clinical events on the computer with the written records.

\section{Methods}

All London practices on the VAMP research bank who had $90 \%$ accurate and complete records between 1 April 1990 and 30 September 1990 were invited to 